\title{
ТРАНСФОРМАЦИЯ ОБРАЗОВАНИЯ:
}

\section{угроза или безграничные возможности?}

\section{О.В. Охлупина}

Аннотация. $B$ последние десятилетия возникает лножество споров о жизнеспособности российского образования. Сторонникали радикальных изменений приводятся доводь о его неэбббективности в новых условиях глобального прехода на иифбру. Школь и вузы пугают поколениел «неподдаюшихся" стандартныли подходали "зетов", большую часть свободного времени проводящих в сети, с клиповьл мьюшлениел, неспособностью долгой концентрации внилания и прочили сложностяли и особенностяли. Противники иибровизации стараются оградить подростков от неограниченного использования гаджетов. Обсуждаются вопросы о разулнол использовании иибровьх устройств, не наносящел вреда здоровью. Весной 2020 года ситуация складьвается такил образол, что "вред" от долговреленного обшения молодежи с гаджетали становится несопоставилыли с возложностью остановки прочесса обучения. Учебнье заведения экстренно переходят на работу в дистаниионнол бборлате. В ходе возникшей ситуаиии - это единственный выход. Переход вскрывает множество проблел, которые по возложности решаются в ходе процесса. Становится очевидныли, что как единственно возложный бборлат работы дистаниионное обучение использовать невозложно. Какил станет образование будущего, будет зависеть от многих фбакторов. Останется оно всеобщил со знакол качества традииионного российского образования или подвергнется радикальной трансборлации? Работодатели делают ставку на креативньх сотрудников, эбббективно справляющихся с лногозадачностью, способных $\kappa$ непрерывнолу салообразованию на протяжении всей жизни. Концепиия life-long learning продолжает оставаться трендол, не сдавая своих позииий. Цель данной статьи - вылснить, так ли сильно отличается новое поколение молодежи, что о его "броню" разбиваются все подходь традииионной систель образования. Или же под фблагол поколения $Z$ продвигается идея коренного перехода к абсолютно новолу образованию.

Ключевые слова: иифровые технологии, теория поколений, поколение $Z$, традиционное образование, дистаниионное обучение, образование будушего. 


\section{TRANSFORMATION OF EDUCATION:}

\section{Threat or Limitless Opportunities?}

\section{O.V. Okhlupina}

Abstract. In recent decades there have been many disputes about the viability of Russian education. Supporters of radical changes argue that it is ineffective in the new conditions of the global transition to digital. Schools and universities are intimidated by a generation of "zetas" who "do not succumb" to standard approaches, spending most of their free time online, with clip thinking, inability to concentrate for a long time, and other difficulties and peculiarities. Opponents of digitalization are trying to protect teenagers from unlimited use of gadgets. There are discussions about how to use digital devices wisely and without harming their health. In the spring of 2020 the situation develops in such a way that the "harm" from the long-term communication of young people with gadgets becomes incomparable with the possibility of stopping the learning process. Educational institutions are urgently moving to work in a remote format. In the course of this situation, this is the only way out. The transition reveals many problems that, if possible, are solved during the process. It becomes obvious that it is impossible to use distance learning as the only possible format of work. What the future will be like depends on many factors. Will it remain universal with a sign of quality of traditional Russian education or will it undergo a radical transformation? Employers rely on creative employees who are efficient in multitasking and capable of continuous self-education throughout their lives. The concept of life-long learning continues to be a trend, without giving up its positions. The purpose of this article is to find out whether the new generation of young people is so different that all approaches of the traditional education system are broken down about their "armor". Or under the flag of Generation $Z$ the idea of a radical transition to a completely new education is being promoted.

Keywords: digital technologies, generation theory, generation $Z$, traditional education, distance learning, education of future.

ложившаяся в начале 2020 г. в мире ситуация, связанная с пандемией, стала своего рода проверкой готовности общества к переменам. Произошла глобальная «обкатка» технологий дистанционного обучения.

Резкий переход выявил множество проблем, которые с различной степенью успешности решались «в по- левых условиях» в ходе процесса. Выявлены как плюсы, так и минусы дистанционного образования. Но очевидно, что убедительных доказательств повышения качества образования с помощью тотальной цифровизации пока не наблюдается.

Мир становится технологичным. И цифрровизация, о которой мы слы- 
шим отовсюду, оказывается составляющей жизни современного общества. Переход к цифрре объясняется необходимостью эфрфективной работы и существования в среде, где стремительно развиваются информационные технологии. Постепенно человек получает доступ к использованию новых возможностей и становится частью информационного общества.

Внедрение цифровых технологий в экономику и образование - стали приоритетными направлениями политики Российского государства, отраженными в [1-3].

\section{Поколение Z: крах привычного}

\section{или «все новое - хорошо забытое старое»?}

В послелние десятилетия широкую известность в мире получила теория поколений У. Штрауса и Н. Хоува, разработанная на основе анализа истории США. Адаптироать эту теорию к реалиям нашей страны постарались Е. Шамис и А. Антипов [4]. Интересен фракт, что в России теорию поколений взяли на вооружение и применяют менеджеры, маркетологи, специалисты по рекламе [5].

Так называемое поколение Z (Internet generation) вызывает к себе больше всего внимания. Сосуществование в реальном и цифровом мире («плавающая картина мира» [6]) становится нормальным явлением для его представителей. Проблемам, связанным с этим, посвящено огромное количество исследований, в которых много говорится об «экранной зависимости», рассредоточении внимания, снижении объема памяти, дегенерации познавательных процессов, снижении качества сна, повышенной возбудимости и т.д. [7]. Специалисты высказывают обеспокоенность столь стремительной цифровизацией детства. Л. Иванова, заместитель заведующего кафедрой клинической фризиологии и нелекарственных методов терапии ФПК МР МИ РУДН, ФГБНУ «Национальный НИИ общественного здоровья им. Н.А. Семашко» считает, что «до широкомасштабного внедрения гаджетов в процесс обучения необходимо провести длительные исследования <..>, а также разработать нормы для их применения, с привлечением психологов, психофизиологов, клиницистов и организаторов здравоохранения» [8]. Однако как бы родители и профессионалы ни пытались уберечь своих детей от неограниченного влияния гаджетов, избежать их использования невозможно. Сложившаяся эпидемиологическая ситуация - яркий тому пример. Министерство просвещения в середине августа 2019 г. опубликовало «Методические рекомендации об использовании средств мобильной связи в общеобразовательных организациях» [9] «с целью снижения негативного влияния на здоровье», а в начале 2020 г. мы столкнулись с массовой цифровизацией процесса обучения.

Сторонники реформы образования также проявили интерес к поколению Z. Стала продвигаться идея о «радикальном» отличии его представителей от всех предыдущих поколений. Как следствие: старые подходы к их обучению утрачивают силу, и спасти ситуацию способна модернизация образования.

Но так ли сильно отличается поколение Z от остальных, что к нему требуются «революционные» подходы в построении образовательного процесса? 
Анализируя характеристики «зетов», мы понимаем, что, например, многозадачность, которую приписывают современным подросткам, продвигаемая как необходимость настоящего времени, - это никак не характеристика поколения. Она присуща, скорее, более старшим людям, так как связана со зрелостью нервной системы. Но даже среди зрелых людей процент способных успешно справляться с многозадачностью невысок. И часто следствием одновременной работы в разных направлениях становится утомляемость, рост ошибок выполнения, неглубокое восприятие информационного потока. Более того, доказано, что режим последовательного решения задач гораздо эфрфективнее [10].

Низкий контроль над концентрацией внимания, характерный «зетам», наблюдался и у представителей других поколений. Согласно Л. Выготскому, подростковый возраст - самый неуравновешенный и изменчивый период. Именно поэтому во время занятий внимание обучаемых стимулируется преподавателем. И постепенно в ходе учебной деятельности учащиеся вырабатывают навык поддержания произвольного внимания [11].

Введенное Э. Тофрфлером, клиповое мышление понимается как «ррагментарное поверхностное знание» [12]. Клиповое мышление можно рассматривать как индивидуальный стиль мышления. Этот вид мышления часто связывают с многозадачностью. Клиповое мышление можно определить как приобретенный вид мышления. Информация поступает без анализа и отражается в сознании клипами, без учета логи- ческих связей между ними, поэтому у ее потребителя не фрормируется целостная картина окружающего мира. Проблемы такое мышление создаст своему обладателю только в том случае, если у человека не развиваются другие виды мышления. Следует вспомнить, что особенностью мыслительной деятельности подростка является формируемое в процессе традиционного обучения постепенно изменение соотношения между конкретно-образным и абстрактным мышлением в пользу абстрактного мышления. Получается, что опасения излишни. Дополнительно приобретаемый навык «клиповости» позволяет быстро находить решение при выполнении поставленных задач.

Можно и дальше анализировать приписываемые молодежи негативные стереотипы ради использования «моральной паники» [13] для продвижения идей трансформации образования. Н.В. Богачева, развеивая «мифы» о поколении Z, пишет: «Проще доказать, что с молодым поколением что-то не так, чем признать, что с ним все в порядке» [14].

\section{Каким станет образование будущего?}

Очевидно, что окружающий мир меняется стремительно, а вместе с ним меняемся и мы. Но так было и раныше. Общество развивалось. Появлялись наукоемкие производства, требующие высококлассных специалистов, постоянно повышающих свою квалификацию. Образование всегда чутко реагировало на подобные вызовы.

Новое время требует специалистов с высоким уровнем интеллекту- 
альной лабильности, способных к самообразованию на протяжении всей жизни. Консервативные методы, по утверждениям специалистов, ратующих за передорматирование образования, уже не работают с прежней эфрективностью. Так, IT-директор СIO (Москва) Д. Песков [15], характеризуя вузы с традиционным подходом, констатирует: «Если больного пичкать допингом, он еще немного попрыгает, но ничего хорошего он уже не сделает, поэтому надо позволить “больному” умереть и построить образовательную систему совершенно иного принципа». То есть речь именно об ином подходе. В чем же его особенности?

Процесс обучения направлен на достижение результата. Система образования нацелена на формирование качеств личности, необходимых обществу для включения в необходимые виды деятельности [16]. Образование ориентируется на удовлетворение потребностей работодателя. Согласно этим требованиям вырабатываются компетенции будущих специалистов. Степень использования компанией-работодателем цифровых технологий напрямую влияет на рост требований к профрессиональному уровню нанимаемого сотрудника, от которого ожидается также готовность работать в условиях быстрой смены технологий и непрерывного саморазвития. «Образование будет все более и более специализированным, профессионалов широкого профиля будет все меньше» [17].

Станет ли образование нового образца доступным для всех без исключения граждан? «В будущем будут разные модели университетов. Фундаментальное образование необ- ходимо, но оно должно стоять на вершине пирамиды... Образование будущего разделится на два вида “компьютерное", оно будет дешевым, и “человеческое”, оно будет дорогим, потому что знания стремительно обесцениваются, а социальные связи и возможность учиться лицом к лицу будут только дорожать» [15]. «Массовость высшего образования неминуемо вступит в противоречие с возможностью отдельных граждан, обладающих повышенным достатком, обеспечить для себя и своих детей особые условия, в то время как провозглашаться будет всеобщая доступность и равенство прав» [17].

Образование постепенно становится сферой бизнеса по оказанию образовательных услуг. Обучаемый приобретает определенные навыки для последующей выгодной их продажи работодателям. Происходит переход к персонализации образования. Предполагается создание универсальной идентификации учащегося. Это позволит фиксировать достижения в базе, выделять наиболее талантливую молодежь. Тем самым возникнет разделение на перспективных сотрудников и «людей одной кнопки». «Поскольку всех учить одинаково хорошо не получится, мы будем вынуждены встать перед выбором: либо помогать самым умным, либо пытаться подтянуть остальных хотя бы до среднего уровня» [там же]. Ясно, что второй вариант — явно не в приоритете.

Да, џифровизация открывает цифрровой доступ к большому количеству учебных материалов. Осваиваются новые методики обучения, совершенствуется удаленное получение знаний. И одновременно делается упор на самостоятельную работу. 
С чем мы реально столкнулись в ходе дистанционного образования? С огромным потоком информации, который обрушился на студентов и учащихся школ. С этим объемом многим пришлось пытаться справляться самостоятельно, получая консультации преподавателей. Но полученная информация у многих не трансформировалась в знания. А ведь именно они являются критерием эффрективности учебного процесса [18]. Информация становится знанием лишь, если она осмыслена, структурирована и может использоваться обучаемым при решении определенных задач. Но мы прекрасно понимаем, что в фрорс-мажорной ситуации любое обучение лучше полного его отсутствия. Поэтому делаем соответствующие выводы по устранению минусов и надеемся, что такой формат не станет единственно фозможным в дальнейшем.

В условиях цифровизации возникает вопрос о возможной замене преподавателя на тьютора [17], посредника между обучаемым и обучающим ресурсом. Это означает девальвацию роли преподавателя, который всегда был центральной фригурой системы образования. «Происходит изменение роли преподавателя. Сегодня он должен сосредоточиться не на изложении материала из одной головы в другую, а на консультировании» [19].

Ответ очевиден: такая замена приведет к негативным последствиям. Именно преподаватель учит обработке, анализу, систематизации, установлению справедливости той или иной информации, мотивирует, оказывает влияние на формирование интереса к выбранному виду профрессиональной деятельности. Он является тем фрильтром и движущей силой, которые необходимы обучаемому, пока тот не научится работать самостоятельно.

Цифровизация порождает преобладание наглядно-образного и наглядно-логического мышления (вспомним о приписываемой поголовно молодежи клиповости мышления), приводя в действие «самоисполняющееся пророчество» [20]. В связи с этим преподавателям рекомендуется использовать новые способы подачи образовательной информации, адаптированные к быстрому восприятию, уходить от традиционных повествовательных форм, требующих словесной подачи нового материала, освоения объемных текстов. Воспринимаемой считается инфографическая информация. На фроне этого снижается продуктивность лекций, не содержащих выраженной проблемной и интерактивной составляющей. И постепенно начинается уход от человека думающего, ведь люди с клиповым мышлением не могут проводить глубокий логический анализ и не могут решать достаточно сложные задачи.

Индивидуализация процесса обучения в дистанционном формате имеет как свои плюсы, так и минусы. Положительным является построение субъективных образовательных направлений и непрерывный индивидуальный мониторинг личностной и профрессиональной результативности обучающихся. Однако персонализация может привести к снижению уровня социализации учащихся, неумению работать в команде, уменьшению соревновательности в учебе, недостаточному уровню развития во- 
левых качеств и инициативности. Возникают вопросы, связанные со способностью ученика себя мотивировать, разрабатывать эффективный план самостоятельного получения знаний, выполнять большой объем работы, контролировать свои знания (может появиться иллюзия собственной компетентности либо существенно снизится самооценка).

Традиционно образование включает в себя воспитание и обучение [21]. Но, если передача информации в сети возможна, то как быть с воспитанием?

Ознакомление молодого поколения с базовыми ценностями, культурой, традициями играет важную роль в становлении личности. Поколению Z свойственна сетевая социализация личности. Она носит хаотический характер. Возникают сложности педагогического процесса, связанные с пробелами в «социальных компетенциях» [22]. Необходимо сделать ход такой социализации контролируемым педагогически. При этом следует учитывать такие характеристики представителей цифрового поколения, как привычка использовать разные источники информации, стремление к самовыражению, предпочтение партнерского типа отношений иерархическому, открытость к межкультурному и межстрановому общению, уверенность в своих силах.

Важно развивать способность разделять виртуальный и реальный миры и соответствующие им типы ответственности.

Необходимо сформировать культуру коммуникации в цифровом пространстве, способность верифицировать и анализировать информацию.
Воспитать социальную ответственность, понимая, что использование цифровых средств повышает риск манипуляций или эксплуатации человека человеком.

Подведем итоги. Развитие технологий изменяет окружающий мир. Применение новейших разработок направлено на улучшение жизни общества. Противиться изменениям глупо и бесполезно. Государству для поступательного движения необходимы инициативные квалифицированные кадры и прорывные технологии. На помощь в достижении поставленных целей, как обычно, должна прийти система образования, чутко реагируя на изменения.

Эпидемия явилась причиной тотального перехода к дистанционному обучению. Непривычная для многих, сырая, недостаточно отработанная система работы позволила продолжить образовательный процесс в экстренных условиях. Что стало несомненным положительным моментом. Однако выявился целый ряд проблем, связанных с этим форматом работы. Вузы и школы должны ответственно подойти к анализу своей деятельности во время пандемии: рассмотреть все сложности и выработать стратегию по их предотвращению, взять на вооружение наиболее «рабочие» методы и усовершенствовать их.

Определенно можно сказать, что дистанционное обучение не может стать полноценной альтернативой очному на постоянной основе. И стоит ли ломать традиционное, доказавшее свою эфрфективность образование и слепо стремиться к новому с сомнительной полезностью? Не рациональнее ли взять лучшее и до- 
полнить его грамотно сконструированным новым?

Не стоит забывать, что гораздо эфрфективнее то общество, где большинство все же подтянуто до средне- го уровня (что абсолютно не исключает наличие талантливых и ярких представителей), чем бесполезная серая масса с низким уровнем образованности.

\section{СПИСОК ИСТОЧНИКОВ И ЛИТЕРАТУРЫ}

1. Указ Президента Российской Федерации от 09.05.2017 №. 203 «О Стратегии развития информационного общества в Российской Федерации на 2017-2030 годы». URL: https://www. garant.ru/products/ipo/prime/doc/71570570/ (дата обращения: 30.04.2020).

2. Постановление Правительства Российской Федерации от 18.04 .2016 г. №. 317 «О реализации национальной технологической инициативы». URL: https://base.garant.ru/71380666/ (дата обращения: 01.05.2020).

3. Распоряжение Правительства Российской Федерацииот 28.07.2017 ою 1632-р «Об утверждении программы “Цифровая экономика Российской Федерации”» (раздел 2 - «Кадры и образование»). URL: http://static.government.ru/media/files/9gFM4FHj4PsB79I5v7yLVuPgu4bvR 7M0.pdf (дата обращения: 01.05.2020).

4. Шамис, E., Антипов, А. Теория поколений. URL: https://psycho.ru/library/2581 (дата обращения: 07.05.2020).

5. Асташова, Ю.В. Теория поколений в маркетинге // Вестник Южно-Уральского государственного университета. 2014. Т. 8. № 1. С. 108-114.

6. Будущее образования: глобальная повестка. URL: http://rusinfoguard.ru/wp-content/ uploads/2016/12/GEF.Agenda_ru_full.pdf (дата обращения 01.05.2020).

7. Зависимость подростков от гаджетов: что делать, если ребенок не отлипает от телефона? URL: https://zen.yandex.ru/media/cognifit/zavisimost-podrostkov-ot-gadjetov-chto-delat-eslirebenok-ne-otlipaet-ot-telefona-5c741868645eac00b39dddbe (дата обращения: 03.05.2020).

8. При «гаджетизации» обучения можно забыть о думающем поколении. URL: http://rvs.su/ novosti/2018/pri-gadzhetizacii-obucheniya-mozhno-zabyt-o-dumayushchem-pokolenii\#hcq=n YxBlVq (дата обращения: 01.05.2020).

9. Методические рекомендации об использовании средств мобильной связи в общеобразовательных организациях. URL: https:/www.rospotrebnadzor.ru/documents/details.php?ELEME NT_ID=12456 (дата обращения: 30.04.2020).

10. Фрумкин, К.Г. Глобальные изменения в мышлении и судьба текстовой культуры // Intermum. 2010. C. 26-36.

11. Бруннер, Е.Ю. К вопросу о психологии произвольного внимания // Гуманитарные науки. 2016. No. 1. C. $42-53$.

12. Тоффлер, Э. Третья волна. М.: АСТ. 2009. 800 с.

13. Моральная паника. URL: https://ru.qwe.wiki/wiki/Moral_panic (дата обращения: 01.05.2020).

14. Поколение Z: почти все, что говорят о нем, - ложь. URL: https:/expert.ru/russian reporter/2019/06/pokolenie-z-pochti-vse-chto-govoryat-o-nem---lozh/ (дата обращения: 01.05.2020).

15. Песков, Д. Обсудим образование будущего: «Google ломает шпиль MГУ». URL: E-xecutive. ru http://safbd.ru/en/content/obrazovanie-budushchego-google-lomaet-shpil-mgu (дата обращения: 30.04.2020). 
16. Саркисьян, Т.Н. Педагогический процесс как целостное явление // Историческая и социально-образовательная мысль. 2014. Т. 6. № 6. Ч. 1. С. 139-143.

17. Главный тренд российского образования - цифровизация // Учительская газета. 2018. URL: http://www.ug.ru/article/1029 (дата обращения: 30.04.2020).

18. Костромина, С.Н., Гнедых, Д.С. Информация и знание: подходы к пониманию процессов усвоения информации и формированию знаний в обучении // Вестник Ленинградского государственного университета им. А.С. Пушкина. 2015. № 2. С. 5-14.

19. Цифровая трансформация образования и драйверы развития. URL: https://www.mgpu.ru/ tsifrovaya-transformatsiya-obrazovaniya-i-drajvery-razvitiya/ (дата обращения: 01.05.2020).

20. Merton, R.K. Social Theory and Social Structure. NY, 1968.

21. Педагогика образование, воспитание, обучение. URL: https://mirznanii.com/a/179285/ pedagogika-obrazovanie-vospitanie-obuchenie/ (дата обращения: 03.05.2020).

22. Колесов, В.И., Смоленская, А.Н., Смоленский, С.И. Сущность определения проблемы в структуре социальной компетентности // Символ науки. 2018. № 8. С. 76-77.

\section{REFERENGES}

1. Astashova Yu.V. Teoriya pokolenij v marketinge, Vestnik Yuzhno-Uralskogo gosudarstvennogo universiteta, 2014, T. 8, No. 1, pp. 108-114. (in Russian)

2. Brunner E.Yu. K voprosu o psihologii proizvolnogo vnimaniya, Gumanitarnye nauki, 2016, No. 1, pp. 42-53. (in Russian)

3. Budushchee obrazovaniya: globalnaya povestka, available at: http://rusinfoguard.ru/wp-content/ uploads/2016/12/GEF.Agenda_ru_full.pdf (accessed: 01.05.2020). (in Russian)

4. Cifrovaya transformaciya obrazovaniya i drajvery razvitiya, available at: https://www.mgpu.ru/ tsifrovaya-transformatsiya-obrazovaniya-i-drajvery-razvitiya/ (accessed: 01.05.2020). (in Russian)

5. Frumkin K.G. Globalnye izmeneniya v myshlenii i sudba tekstovoj kultury, Intermum, 2010, pp. 26-36. (in Russian)

6. Glavnyj trend rossijskogo obrazovaniya - cifrovizaciya, Uchitelskaya gazeta, 2018, available at: http://www.ug.ru/article/1029 (accessed: 30.04.2020). (in Russian)

7. Kolesov V.I., Smolenskaya A.N., Smolenskij S.I. Sushchnost opredeleniya problemy v strukture socialnoj kompetentnosti, Simvol nauki, 2018, No. 8, pp. 76-77. (in Russian)

8. Kostromina S.N., Gnedyh D.S. Informaciya i znanie: podhody k ponimaniyu processov usvoeniya informacii i formirovaniyu znanij v obuchenii, Vestnik Leningradskogo gosudarstvennogo universiteta im. A.S. Pushkina, 2015, No. 2, pp. 5-14. (in Russian)

9. Merton Robert K. Social Theory and Social Structure. New York, 1968.

10. Metodicheskie rekomendacii ob ispolzovanii sredstv mobilnoj svyazi v obshcheobrazovatelnyh organizaciyah, available at: https:/www.rospotrebnadzor.ru/documents/details.php?ELEMENT_ $\mathrm{ID}=12456$ (accessed: 30.04.2020). (in Russian)

11. Moralnaya panika, available at: https://ru.qwe.wiki/wiki/Moral_panic (accessed: 01.05.2020). (in Russian)

12. Peskov D. Obsudim obrazovanie budushchego: "Google lomaet shpil MGU", E-xecutive.ru, available at. http://safbd.ru/en/content/obrazovanie-budushchego-google-lomaet-shpil-mgu (accessed: 30.04.2020). (in Russian)

13. Pedagogika obrazovanie, vospitanie, obuchenie, available at: https://mirznanii.com/a/179285/ pedagogika-obrazovanie-vospitanie-obuchenie/ (accessed: 03.05.2020). (in Russian) 
14. Pokolenie Z: pochti vse, chto govoryat o nem, — lozh, available at: https://expert.ru/russian reporter/2019/06/pokolenie-z-pochti-vse-chto-govoryat-o-nem---lozh/ (accessed: 01.05.2020). (in Russian)

15. Postanovlenie Pravitelstva Rossijskoj Federaciiot 18.04.2016 g. No. 317 "O realizacii nacionalnoj tekhnologicheskoj iniciativy”, available at: https://base.garant.ru/71380666/ (accessed: 01.05.2020). (in Russian)

16. Pri "gadzhetizacii" obucheniya mozhno zabyt o dumayushchem pokolenii, available at: http://rvs. su/novosti/2018/pri-gadzhetizacii-obucheniya-mozhno-zabyt-o-dumayushchem-pokolenii\# hcq $=\mathrm{nYxBlVq}$ (accessed: 01.05.2020). (in Russian)

17. Rasporyazhenie Pravitelstva Rossijskoj Federaciiot 28.07.2017 No. 1632-r "Ob utverzhdenii programmy 'Cifrovaya ekonomika Rossijskoj Federacii", (razdel 2 - "Kadry i obrazovanie"), available at: http://static.government.ru/media/files/9gFM4FHj4PsB79I5v7yLVuPgu4bvR7M0.pdf (accessed: 01.05.2020).

18. Sarkisyan T.N. Pedagogicheskij process kak celostnoe yavlenie, Istoricheskaya i socialno-obrazovatelnaya mysl, 2014, T. 6, No. 6, Ch. 1, pp. 139-143. (in Russian)

19. Shamis E., Antipov A. Teoriya pokolenij, available at: https://psycho.ru/library/2581 (accessed: 07.05.2020). (in Russian)

20. Toffler E. Tretya volna. Moscow, AST, 2009, 800 p. (in Russian)

21. Ukaz Prezidenta Rossijskoj Federacii ot 09.05.2017 No. 203 "O Strategii razvitiya informacionnogo obshchestva $v$ Rossijskoj Federacii na 2017-2030 gody”, available at: https://www.garant. $\mathrm{ru} /$ products/ipo/prime/doc/71570570/ (accessed: 30.04.2020). (in Russian)

22. Zavisimost podrostkov ot gadzhetov: chto delat, esli rebenok ne otlipaet ot telefona? Available at: https://zen.yandex.ru/media/cognifit/zavisimost-podrostkov-ot-gadjetov-chto-delat-eslirebenok-ne-otlipaet-ot-telefona-5c741868645eac00b39dddbe (accessed: 03.05.2020). (in Russian)

Охлупина Ольга Валентиновна, кандидат физико-математических наук, доцент, кафедра математики, Брянский государственный инженерно-технологический университет, helga131081@yandex.ru

Okhlupina O.v., PhD in Physical and Mathematics, Associate Professor, Mathematics Department, Bryansk State University of Engineering and Technology, helga131081@yandex.ru 